\title{
Stevia : A True Glycoside Used as a Sweetener and Not Affecting Behavior
}

\author{
Marie-Claire Cammaerts ${ }^{1 *}$, Axel Dero ${ }^{2}$ and Roger Cammaerts ${ }^{3}$ \\ 'Université Libre de Bruxelles, Faculté des Sciences, Département de Biologie des Organismes, \\ CP 160/12, 50, Av. F.D. Roosevelt, 1050, Bruxelles, Begium; mtricot@ulb.ac.be \\ 2Université Libre de Bruxelles, Laboratory of Bio, Electro and Mechanical Systems, \\ CP 165/56, Av F.D. Roosevelt, 1050, Bruxelles, Belgium; axel.dero@ulb.ac.be \\ ${ }^{3}$ Independent Researcher, Bruxelles, Belgium; rcammaer@ulb.ac.be
}

\begin{abstract}
Using ants as models, the glycoside rebaudioside A, a sweetener extracted from the plant Stevia rebaudiana and commercialized under the name 'stevia', was shown to have no effect on their food consumption, locomotion, precision of reaction, response to pheromones, brood caring, cognition, visual and olfactory conditioning and memory, although this sweetener slightly increased the ants audacity. However, when having the choice between stevia and saccharose, the ants somewhat preferred the latter. Stevia is thus a safe sweetener which does not impact general health, behavior and cognition, but it is generally perceived less pleasant than saccharose.
\end{abstract}

Keywords: Cognition, Food Consumption, Locomotion, Memory

\section{Introduction}

Sugar is universally consumed. It does not cause chronic or acute diseases at a moderate consumption level ${ }^{1}$. However, today, sweeteners attract consumers who want to control their weight or are insulin deficient ${ }^{2}$. These substances duplicate the taste of sugar, while providing less energy. They are largely consumed all over the world either simply instead of sugar or as a constituent of beverages (soda, ice tea, energizing drinks ...) or food (yogurts, creams, cakes ...). The conclusions of the numerous studies carried out on sweeteners range from 'safe under all conditions' to 'unsafe at any dose'. A survey $^{2}$ explores these controversies. Among the 23 natural sweeteners and the 12 artificial ones listed in this review, the most safe, easily available and commonly consumed ones are aspartame, stevia and saccharine. In Europe and North America, the most used is aspartame which has a very nice sweeten taste. We have analyzed the effects of aspartame using ants as biological model $\mathrm{s}^{3}$ and concluded that this sweetener, intact, does not severely impact health, but has some adverse effects. Being not a glycoside though giving to the brain the 'presence of sugar' information, it impacts behavior. It increases the ant's speed of locomotion, audacity and food consumption. It reduces their precision of reaction, cognition and memory. In his review ${ }^{2}$, Tandel reports the effects of aspartame available in literature ${ }^{4}$, and the author's conclusion is in agreement with our own one. He states that aspartame is safe at current levels of consumption, has no strong adverse effects while intact, but presents dangers because it gives rise to phenylalanine which impacts the brain, may induce headache, and hydrolyzes finally into dangerous compounds. Moreover, giving to the brain the 'sugar' information though being not a sugar, aspartame may alter physiology and behavior, a fact we also stated. Saccharine was shown to increase body weight, and high consumption levels may cause bladder cancer ${ }^{2}$. It is actually less and

${ }^{*}$ Author for correspondence 
less consumed. In Tandel's list of the most consumed and approved sweeteners ${ }^{2}$, stevia is the top one. The commercial product 'stevia' contains the glycosides extracted from the South American plant Stevia rebaudiana, presently also cultivated in Asia. The main compounds are steviosides and the sweetest one, rebaudioside A (Figure 1$)^{5}$. This substance is about 200 times sweeter than saccharose so that a very small amount of it can be used instead of usual amount of sugar ${ }^{6}$. It is stable under normal food and beverage conditions as well as under cooking. It is poorly soluble in water but in the commercial product 'stevia', it is mixed with sodium bicarbonate which largely increases its solubility ${ }^{7}$. Clinical studies have shown that stevia is safe, or has a very low acute toxicity ${ }^{8}$. However, high doses may have adverse effects because a metabolite compound of stevia is steviol which is not without danger for pregnant females and fetuses (see the Discussion section). The commercial 'stevia' is used in South America and Asia since long time, and was allowed in USA in 1995. In Europe, it was still rejected up to 1999, then estimated being not risky in 2006, and finally approved in 2011 as a food additive by the European Commission. Progressively easier to find in drugstores and shops, stevia has received the code E 960. However, Health Canada still does not approve stevia as a food additive $e^{5,6}$. It remains to know to which extent humans can consume stevia instead of sugar without imperiling their health. Is the quantity of glucose supplied by stevia sufficient to avoid effects due to lack of glucose while 'sugar' information is given to the brain? Diabetic persons and those wanting to limit their sugar consumption should be informed about the possible physiological and ethological consequences of consuming stevia instead of sugar.

Three weeks after having examined the effects of aspartame on ants used as biological models ${ }^{3}$, we observed

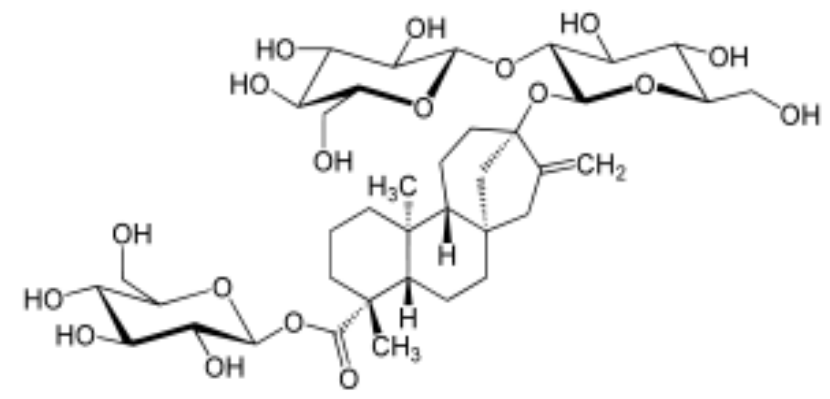

Figure 1. Chemical structure of rebaudioside A, the most sweetened glycoside extracted from the plant Stevia rebaudiana, a sweetener used in South America and Asia. that the six colonies we used for this study had recovered and were in good health, very probably because we had alternated time periods of sugar diet and of aspartame diet. Note that a duration of three weeks (= 21 days) for ants roughly corresponds to a time period of 21 months for humans. We then aimed to examine physiological and ethological effects of stevia using exactly the same experimental material, protocols and methods. Thus, in the present work, using ants as biological models (1), we examine with no conflict of interest (2) the insects' food consumption, locomotion (linear and angular speed), precision of reaction, response to pheromones, 'audacity', brood caring behavior, cognition, visual and olfactory conditioning and memory, stevia acceptance and stevia consumption (3).

\subsection{Why using Ants as Biological Models?}

Most biological processes are similar for all animals, including humans (i.e. genetics, metabolism, nervous cells functioning). Consequently, a lot of invertebrates and vertebrates are used as models for studying biology9. Invertebrates are more and more used because they offer scientists advantages, such as a short life cycle, a simple anatomy, and being available in large numbers $^{10}$. Some species are largely used, for instance, the flatworm Dendrocelium lacteum, the nematode worm Caenorhabdotes elegans, the mollusk Aplysia californica, the beetle Tribolium castaneum, the fruit fly Drosophila melanogaster, and the domestic bee Apis mellifera. Among the invertebrates, insects, especially social hymenoptera and among them, bees, are advantageously used as models ${ }^{11}$, but ants too can be used. Indeed, colonies containing thousands of ants can be maintained in laboratories, at low cost and conveniently, throughout the entire year. Ants are among the most complex and social invertebrate animals as for their morphology, physiology, social organization and behavior. They are among the most morphologically evolved hymenoptera, having a unique resting position of their labium, mandibles and maxilla ${ }^{12}$, as well as a lot of glands emitting numerous efficient pheromones ${ }^{12}$. Their societies are highly organized with a strong division of labor, an age-based polyethism and a social regulation ${ }^{12}$. Their behavior is well developed: they care for their brood, build sophisticated nests, chemically mark the inside of their nest, and differently, their nest entrances, nest surroundings and foraging area ${ }^{12}$. They generally use an alarm signal, a trail pheromone, and a 
recruitment signal ${ }^{12}$; they are able to navigate using memorized visual and olfactory cues ${ }^{13}$; they efficiently recruit nestmates where, when and as long as it is necessary ${ }^{14}$ and finally, they clean their nest and provide their area with cemeteries ${ }^{14}$. According to the complexity of their society and their behavior, it looks reasonable to use ants as biological models for studying physiological and ethological effects of substances, treatments or situations.

During many years, we worked on ant species belonging to the genus Myrmica, and among others, on Myrmica rubra (Linnaeus 1758). We know some of its annual cycle $^{15}$, its ecological traits, eye morphology ${ }^{16}$, subtended angle of vision ${ }^{17}$, visual perception ${ }^{18}$, navigation system ${ }^{13}$, visual and olfactory conditioning capabilities ${ }^{19}$, and recruitment strategy ${ }^{20}$. The ontogenesis of cognitive abilities of Myrmica species, has also been approached ${ }^{21}$. Studies on the impact of age, activity and diet on the conditioning capability of the related species $M$. ruginodis Nylander $1846^{22}$ led to presume that ants could be good biological models. This was confirmed while studying the effects of caffeine, theophylline, cocaine, and atropine, of nicotine ${ }^{23}$, morphine and quinine, fluoxetine (an 'ISRS' antidepressant), anafranil (an 'ACT' antidepressant) and efexor (an 'IRSNa' antidepressant), carbamazepine, and finally buprenorphine and methadone ${ }^{24}$. Each time, we observed effects related to those observed on humans, and brought information and precision on them. Thus, we here used ants of the species M. rubra for examining effects of stevia.

\subsection{Why Have We no Conflict of Interest?}

The few studies already made about stevia could have been performed with some conflict of interest since made by assistants of stevia furnishers (who hope stevia has no adverse effect) or by practitioners (who want to protect humans against potential adverse effects). As for us, making only fundamental research on ants, we have no conflict of interest.

\subsection{Why are the planned analyses possible?}

We can easily assess the ants complete food consumption, this food being given on the foraging area, at a visible place. We can assess the ants' locomotion (linear and angular speed), precision of reaction (orientation towards an alarm signal), response to a pheromone (trail following behavior), and audacity. We are accustomed to assess the ants' acquisition of a visual and an olfactory conditioning, as well as their visual or olfactory memory. We can assess the ants' brood caring and cognition. We have set up an experimental protocol for assessing the ants' preference between two different foods, or aversion of a food. We can quantify the ants' consumption of aqueous solution of stevia or sugar.

We are thus in the best conditions possible for studying the effects of stevia on these ants' ethological and physiological traits versus these traits under sugar diet. Finally, we can compare our observations with those previously made with aspartame under exactly the same experimental conditions ${ }^{3}$.

\section{Experimental Planning}

Working on six experimental ant colonies maintained under a stevia diet, we successively assessed, in comparison with what occurred under sugar diet:

- the ants' complete food consumption,

- the ants' locomotion, precision of reaction, trail following behavior, and audacity,

- the ants' ability in acquiring visual and olfactory conditioning, as well as their visual and olfactory memory,

- the ants' brood caring behavior and cognition,

- the ants' preference between sugar water and an aqueous solution of stevia,

- the ants' consumption of an aqueous solution of stevia, and later on of sugar

We then summarized our findings and compared them to those obtained on the same ants under aspartame diet $^{3}$. Before concluding, we discuss our results and confront them with what is actually known about the effects of stevia and aspartame.

\section{Materials and Methods}

\subsection{Collection and Maintenance of Ants}

The effects of stevia were studied on 6 colonies of $M$. rubra labeled A to F. Colony A was collected in an abandoned slate quarry located in the Aise valley (Ardenne, Belgium). Colony B was collected at Dour (Hainaut, Belgium) on the abandoned coal mining slag heap St Charles. The colonies C, D, E and F were collected at Haine St Paul (Hainaut, Belgium), on the slag heap named Chef Lieu. All the colonies were maintained in the laboratory 
in artificial nests made of one to three glass tubes halffilled with water, a cotton-plug separating the ants from the water. The glass tubes were deposited in trays $(34 \mathrm{~cm} \mathrm{x}$ $23 \mathrm{~cm} \mathrm{x} 4 \mathrm{~cm}$ ), which internal sides were slightly covered with talc to prevent the ants from escaping. These trays served as foraging areas, food being delivered in them. The ants were fed with sugar water provided ad libitum in a small glass tube plugged with cotton, and with Tenebrio molitor larvae (Linnaeus 1758) provided twice a week on a glass slide. During experiments, the sugar water was replaced by an aqueous solution of stevia delivered to the ants as their usual sugar water. Temperature was maintained between $18^{\circ} \mathrm{C}$ and $22^{\circ} \mathrm{C}$ and the relative humidity was circa $80 \%$. Lighting had a constant intensity of 330 lux while caring for the ants, training and testing them. During other time periods, lighting was dimmed to 110 lux. The ambient electromagnetic field had an intensity of 2-3 $\mu \mathrm{W} / \mathrm{m}^{2}$. All the members of a colony are here named nestmates, as commonly done by researchers on social hymenoptera.

\subsection{Aqueous Solution of Stevia}

Stevia was furnished by the pharmacist J. Cardon (1050, Bruxelles) in the form of tablets containing $21 \mathrm{mg}$ of stevia, made by the manufacturer 'Axone Pharma SA' (Braine L'Alleud, Belgium). According to the manufacturer, one tablet of stevia provides the sweetness of one small spoon of sugar, e.g. one tablet should be used for 150-200 ml drink. However, the aqueous solution of stevia to be given to the ants must be equivalent in sweetness to the sugar water they usually consume in the wild and in laboratory, which is nearly saturated in glycosides (glucose, saccharose ...). For instance, to feed them in laboratory, we pour ten small (coffee) spoons of brown sugar $(=5$ gr $\times 10=$ $50 \mathrm{gr}$ ) into $150-200 \mathrm{ml}$ of tap water to obtain a sugared solution the ants obviously appreciate. For obtaining the same sugared taste using stevia, ten tablets must be dissolved into $150-200 \mathrm{ml}$ of water. We made thus for the ants an aqueous solution of stevia by pulverizing, then dissolving ten tablets of 'stevia' into $150 \mathrm{ml}$ of water. Note that, as insects proportionally consume about ten times less water than mammals, for feeding ants with a quantity of stevia proportionally similar to that consumed by humans, we should, as a matter of course, use a solution of ten tablets into $150 \mathrm{ml}$ water. Five $\mathrm{ml}$ of that solution were poured into the kind of small tubes usually used to provide the ants with sugar water. The tubes were plugged with cotton which was refreshed each two days, while the entire solution was renewed every five or seven days. Note that the glycosides of stevia are stable even in water. It was checked each day if ants consumed the solution of stevia. The ants effectively consumed it, but were less numerous in doing so than in consuming their usual sugar water, a trait we quantified at the end of the experimental work.

\subsection{Ants' Complete Food Consumption}

For assessing the ants' meat food consumption under stevia diet, we counted during five consecutive days, twice each day, exactly at the same time and under the same conditions (giving food or not, $\mathrm{t}^{\circ}$, humidity, light) as when we did so for ants under sugar diet, the ants of the 6 colonies present on the provided T. molitor larvae (Table 1, daily counts; Figure 2 A). We then established the mean value per day ( $=$ mean of 6 x $2=12$ counts; in total 5 mean values; Table 1, daily means), as well as the mean of all counts performed (Table 1). The five mean values per day obtained for stevia diet were compared to the five mean values previously obtained for sugar diet using the non parametric test of Wilcoxon ${ }^{25}$.

\subsection{Ants' Locomotion (Linear and Angular Speed) and Ants' Precision of Reaction (Orientation Towards an Alarm Signal)}

The assessments were made on ants moving on their foraging area. For each assessment, the movement of five ants of each colony ( $\mathrm{n}=6 \times 5=30$ ants) was analyzed. Ants' linear and angular speed was assessed without presenting any stimulus to the ants. Ants' orientation towards an alarm signal (which allowed examining the ants' precision of reaction) was assessed by presenting to the ants an isolated worker's head. Such head, with widely opened mandibles, is a source of alarm pheromone identical to that of an alarmed worker, in terms of dimensions of the emitting source (the glands opening) and the quantity of pheromone emitted ${ }^{26}$.

Trajectories were manually recorded using a waterproof marker pen, on a glass slide horizontally placed 3 $\mathrm{cm}$ above the experimental tray area. A metronome set at 1 second was used as a timer for assessing the total time of each trajectory. Each trajectory was recorded until the ant reached the stimulus or walked for about $6 \mathrm{~cm}$. All the trajectories were then copied with a water-proof marker pen onto transparent polyvinyl sheets, which could be affixed to a PC monitor screen and remained in place due to their own static electricity charge. The trajectories were 
Table 1. Effect of stevia on meat food consumption

\begin{tabular}{|c|c|c|c|c|c|c|c|c|c|c|c|c|}
\hline \multirow{2}{*}{$\begin{array}{r}\text { Diets: } \rightarrow \\
\text { Colonies: }\end{array}$} & \multicolumn{6}{|c|}{ Sugar water } & \multicolumn{6}{|c|}{ Solution of stevia } \\
\hline & A & B & $\mathrm{C}$ & $\mathrm{D}$ & $\mathrm{E}$ & $\mathrm{F}$ & A & B & $\mathrm{C}$ & $\mathrm{D}$ & $\mathrm{E}$ & $\mathrm{F}$ \\
\hline \multicolumn{13}{|c|}{ Daily counts } \\
\hline \multirow[t]{2}{*}{1} & 1 & 1 & 2 & 0 & 2 & 1 & 3 & 2 & 0 & 1 & 0 & 1 \\
\hline & 0 & 3 & 2 & 0 & 1 & 1 & 4 & 1 & 0 & 1 & 0 & 1 \\
\hline \multirow[t]{2}{*}{2} & 0 & 0 & 0 & 1 & 2 & 0 & 1 & 0 & 0 & 0 & 1 & 1 \\
\hline & 0 & 1 & 0 & 0 & 1 & 0 & 1 & 1 & 1 & 0 & 0 & 1 \\
\hline \multirow[t]{2}{*}{3} & 2 & 1 & 0 & 0 & 4 & 0 & 4 & 1 & 1 & 0 & 0 & 0 \\
\hline & 1 & 2 & 0 & 2 & 1 & 1 & 3 & 2 & 0 & 0 & 0 & 0 \\
\hline \multirow[t]{2}{*}{4} & 0 & 0 & 0 & 0 & 5 & 0 & 3 & 0 & 0 & 0 & 1 & 0 \\
\hline & 1 & 0 & 0 & 0 & 3 & 0 & 3 & 1 & 0 & 1 & 0 & 0 \\
\hline \multirow[t]{2}{*}{5} & 3 & 3 & 0 & 0 & 9 & 1 & 2 & 1 & 0 & 1 & 1 & 1 \\
\hline & 5 & 2 & 0 & 3 & 9 & 1 & 3 & 2 & 0 & 2 & 2 & 1 \\
\hline \multicolumn{13}{|c|}{ Daily means } \\
\hline 1 & \multirow{2}{*}{\multicolumn{6}{|c|}{1.17}} & \multicolumn{6}{|c|}{1.17} \\
\hline 2 & \multirow{2}{*}{\multicolumn{6}{|c|}{0.42}} & \multicolumn{6}{|c|}{0.50} \\
\hline 3 & \multirow{2}{*}{\multicolumn{6}{|c|}{$\begin{array}{l}1.17 \\
075\end{array}$}} & \multicolumn{6}{|c|}{0.92} \\
\hline 4 & \multirow{2}{*}{\multicolumn{6}{|c|}{$\begin{array}{l}0.75 \\
3.00\end{array}$}} & \multicolumn{6}{|c|}{0.75} \\
\hline 5 & & & & & & & & & & & & \\
\hline \multicolumn{13}{|c|}{ Total mean } \\
\hline $1-5$ & \multicolumn{6}{|c|}{1.30} & \multicolumn{6}{|c|}{0.94} \\
\hline
\end{tabular}
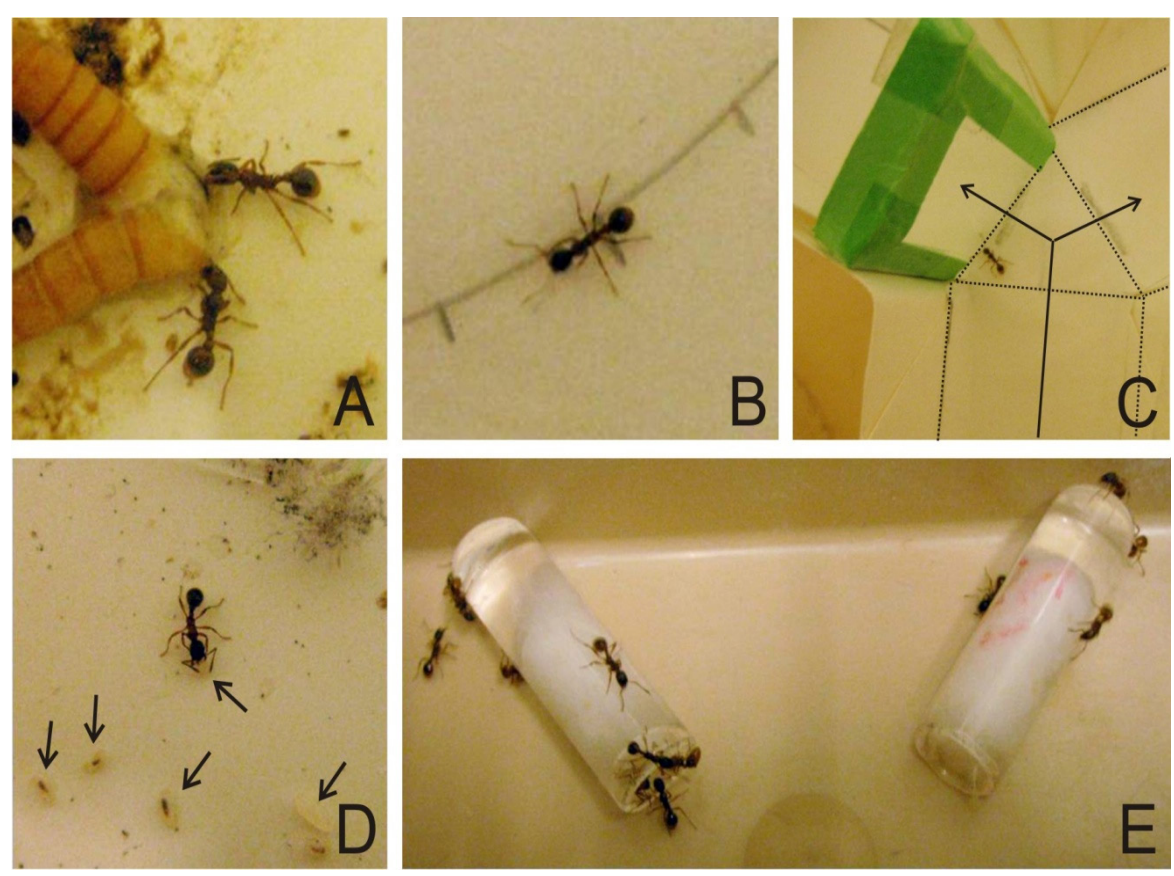

Figure 2. Some views of the experiments. A: under stevia diet, only few ants came eating a Tenebrio molitor larva. B: an ant under stevia diet dully following a trail. C: an ant under stevia diet, previously trained to a hollow green cube, and tested in a Y apparatus, correctly choosing the way provided with a green arch. The limits of the branches of the apparatus have been drawn in dotted lines on the photo; black arrows indicate the possible ways to go. D: an ant under stevia diet taking care of a larva, the later being transported between the ant's mandibles; arrows point to larvae. E: having the choice between a sugar solution (on the left) and one of stevia (on the right), the ants preferred the solution of sugar. 
analyzed using specifically designed software ${ }^{27}$, each trajectory being entered in the software by clicking as many points as wanted with the mouse and by entering then the location of the presented worker's head. After that, the total time of the trajectory was entered, and the software was asked to calculate three variables defined as follows:

The linear speed $(\mathrm{V})$ of an animal is the length of its trajectory divided by the time spent moving along this trajectory. It was here measured in $\mathrm{mm} / \mathrm{s}$.

The angular speed (S) (i.e. the sinuosity) of an animal's trajectory is the sum of the angles, measured at each successive point of the trajectory, made by each segment 'point $\mathrm{i}$ to point $\mathrm{i}-1$ ' and the following segment 'point $\mathrm{i}$ to point $i+1$, divided by the length of the trajectory. This variable was here measured in angular degrees $/ \mathrm{cm}$.

The orientation $(\mathrm{O})$ of an animal towards a given source (here a small blank piece of paper used as a control or an ant's head) is the sum of the angles, measured at each successive point of the recorded trajectory, made by each segment 'point $i$ of the trajectory - given source' and each segment 'point $\mathrm{i}-$ point $\mathrm{i}+1$ ', divided by the number of measured angles. This variable $(\mathrm{O})$ was here measured in angular degrees. When $\mathrm{O}$ equals $0^{\circ}$, the observed animal perfectly orients itself towards the given source; when it equals $180^{\circ}$, the animal fully avoids the source; when $\mathrm{O}$ is lower than $90^{\circ}$, the animal has a tendency to orient itself towards the source and when it is larger than $90^{\circ}$, the animal has a tendency to avoid the source.

Each distribution of 30 values was characterized by its median and quartiles (since being not Gaussian) and the distributions obtained for ants under stevia diet were compared to those previously obtained for ants under sugar diet using the non-parametric $\chi^{2}$ test ${ }^{25}$. Two distributions were considered as statistically different when $\mathrm{P}$ $<0.05$.

\subsection{Ants' Trail Following Behavior}

This behavior was assessed on colonies A, B, D, and E for examining the ants' response to pheromones. The trail pheromone of Myrmica ants is produced by the workers' poison gland. Ten of these glands were isolated in $0.5 \mathrm{ml}$ $(500 \mu \mathrm{l})$ hexane and stored for $15 \mathrm{~min}$ at $-25^{\circ} \mathrm{C}$. To perform one experiment, $0.05 \mathrm{ml}(50 \mu \mathrm{l})$ of the solution was deposited, using a metallic normograph pen, on a circle $(\mathrm{R}=5 \mathrm{~cm})$ pencil drawn on a piece of white paper and divided into 10 angular degrees arcs. One minute later, the piece of paper was placed in the ants' foraging area.
When an ant came into contact with the trail, its movement was observed (Figure $2 \mathrm{~B}$ ). Its response was assessed by the number of arcs of 10 angular degrees it walked without departing from the trail, even if it turned back on the trail. If an ant turned back when coming in front of the trail, its response was assessed as "zero arc walked"; when an ant crossed the trail without following it, its response equaled "one walked arc". Before testing the ants on a trail, they were observed on a "blank" circumference imbibed with $50 \mu$ l of pure hexane, and the control numbers of walked arcs were so obtained (Table 2). On experimental trails, Myrmica workers do not deposit their trail pheromone because they do so only after having found food or a new nest site. For each control and test experiment, 10 individuals of each colony were observed $(\mathrm{n}=4 \times 10$ $=40$ ). Each distribution of values was characterized by its median and quartiles (since being not Gaussian). The distribution of values obtained for ants under stevia diet was compared to that previously obtained for ants under sugar diet using the non parametric $\chi^{2}$ test ${ }^{25}$.

\subsection{Ants' Audacity}

This trait was assessed on colonies A, B, D, and E. A cylindrical tower built in strong white paper (Steinbach ${ }^{\circledR}$, height $=4 \mathrm{~cm}$; diameter $=1.5 \mathrm{~cm}$ ) was set on the ants' foraging area, and the ants present on it, at any place, were counted 10 times, in the course of $10 \mathrm{~min}$. The mean and the extreme values of the obtained values were established (Table 2) and the obtained values were compared to those obtained for ants under sugar diet using the non parametric Mann-Whitney U test ${ }^{25}$.

\subsection{Ants' Conditioning Ability and Memory}

These traits were examined on colonies A, B, D and E. Briefly, at a given time, either a green hollow cube or pieces of fennel were set above or aside respectively the pieces of T. molitor larvae given as food, the ants undergoing so either visual or olfactory operant conditioning. Tests were then performed in the course of time, while the ants were expected to acquire conditioning then, after having removed the green hollow cube or the pieces of fennel, while the ants were expected to partly lose their conditioning.

In detail, ants were collectively visually trained to a green hollow cube constructed of strong paper (Canson $\left.{ }^{\circledR}\right)$ according to the instructions given in $^{28, \text { Figure } 3 \text {, upper part }}$ and set over the meat food which served as a reward. The 
Table 2. Effect of stevia on five ethological and physiological traits. The table gives the median (and quartiles) for the first four traits and the mean [and extremes] of the last one

\begin{tabular}{|l|c|c|}
\hline \multicolumn{1}{|c|}{ Diet $\rightarrow$} & Sugar water & Solution of stevia \\
\hline linear speed, $\mathrm{mm} / \mathrm{s}$ & $13.7(12.3-15.4)$ & $13.1(11.1-15.3)$ \\
\hline angular speed, angular degrees/cm & $135(115-157)$ & $142(111-160)$ \\
\hline orientation, angular degrees & $30.8(27.7-38.3)$ & $33.7(25.2-48.6)$ \\
\hline trail following, $\mathrm{n}^{\circ}$ of walked arcs & $\begin{array}{c}\text { blank: } 1.0(1.0-1.0) \\
\text { test: } 10.0(8.0-16.0)\end{array}$ & $\begin{array}{c}\text { blank: } 1.0(1.0-1.0) \\
\text { test: } 9.0(5.8-16.3)\end{array}$ \\
\hline audacity, mean $\mathrm{n}^{\circ}$ of ants & $0.85[0-3]$ & $1.38[0-3]$ \\
\hline
\end{tabular}

Table 3. Effect of stevia on ants' visual and olfactory conditioning ability and memory

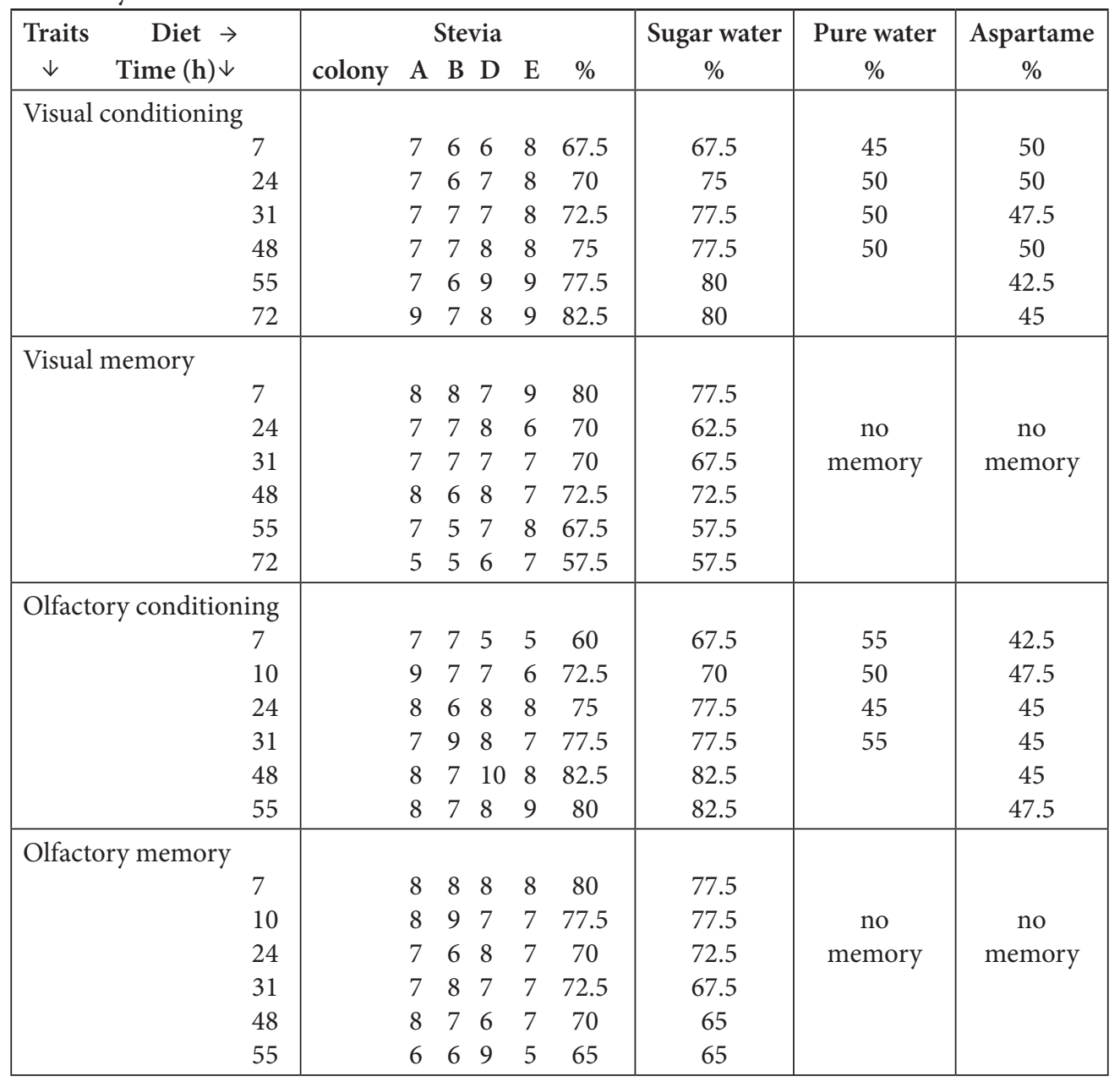

color has been analyzed to determine its wavelengths reflection ${ }^{29}$. The ants could see the cube and easily enter it. Choosing the way with the green arch was the 'correct' choice when ants were tested as explained below. The ants were olfactory conditioned by setting pieces of fennel aside the pieces of T. molitor larva. Choosing the way with the pieces of fennel was the 'correct' choice when ants were tested.

Ants were individually tested in a Y-shaped apparatus (Figure 2 C) constructed of strong white paper according to the instructions given in ${ }^{28}$, Figure 3 , middle part, and set in a small tray $(30 \mathrm{~cm} \times 15 \mathrm{~cm} \times 4 \mathrm{~cm})$, apart from the colony's 
tray. Each colony had its own Y apparatus, which had its own bottom and its sides slightly covered with talc to prevent the ants from escaping. In the Y-apparatus, the ants deposited no trail since being not rewarded. However, they could utilize other chemical secretions as traces. As a precaution, the floor of each Y-apparatus was changed between tests. The Y-apparatus was provided with either a

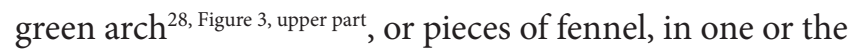
other branch. Half of the tests were conducted with the arch or the odorous plant in the left branch and the other half with the arch or the odorous plant in the right branch of the Y maze, and this was randomly chosen. Control experiments had previously been made on never conditioned ants and on trained ants of colonies being under sugar water $\operatorname{diet}^{19, \text { Tables } 1 \text { and } 2}$. This had to be done because, once an animal is conditioned to a given stimulus, it becomes no longer naïve for such an experiment. It was thus impossible to perform, on the same ants, conditioning first under sugar diet, then under stevia diet. The only solution was to use previous results obtained in the course of identical experiments made on similar colonies being under sugar diet ${ }^{19}$.

To conduct a test on a colony, 10 workers - randomly chosen from the workers of that colony - were transferred one by one onto the area at the entrance of the Y-apparatus. Each ant was observed until it turned to the left or to the right in the Y-apparatus, and its choice was recorded. Only the first choice of the ant was recorded and this only when the ant was entirely under the cube, i.e. beyond a pencil drawn line indicating the entrance of a branch (Figure $2 \mathrm{C}$ ). Afterwards, the ant was removed and transferred into a polyacetate cup, which inner border was covered with talc, until 10 ants were tested, this avoiding testing twice the same ant. All the tested ants were then placed back on their foraging area. For each test, we recorded the numbers of ants $(n=10 \times 4=40$ ants) which chose the "correct" way with the green arch or the pieces of fennel, or went to the "wrong" empty branch of the Y. The percentage of correct responses for the tested ant population was so established (Table 3). The results here obtained for ants under stevia diet were compared to those previously obtained for ants under sugar water $\operatorname{diet}^{19}$, using the non parametric Wilcoxon test ${ }^{25}$.

\subsection{Ants' Brood Caring}

This trait was assessed on colonies $\mathrm{C}$ and $\mathrm{F}$ which contained numerous larvae. A few larvae were removed from the inside of the nest and deposited in front of the nest entrance. Five of them were carefully observed, as well as the ants' behavior in front of a larva (Figure $2 \mathrm{D}$ ). The larvae among the five observed ones still remaining out of the nest after 5 seconds, 2, 4, 6, 8, and 10 minutes were counted, and the numbers recorded for each colony were added (Table 4). The results obtained for ants under stevia diet were compared to those previously obtained for ants under sugar diet using the non parametric Wilcoxon test $\mathrm{t}^{25}$.

\subsection{Ants' Cognition}

The assessment was made on ants of colonies B and E using an experimental apparatus schematically presented in ${ }^{23}$. This apparatus consisted in a small tray $(15 \mathrm{~cm} \mathrm{x} 7$ $\mathrm{cm} \times 4.5 \mathrm{~cm}$ ) inside of which pieces of white extra strong paper (Steinbach ${ }^{\circledR}, 12 \mathrm{~cm} \mathrm{x} 4.5 \mathrm{~cm}$ ) were inserted in order to create a way with twists and turns between a loggia too narrow for 15 ants (the initial loggia) and a larger one (the free loggia). Two experimental apparatus were built and used, each one, for one of the two colonies. Each time 15 ants were collected from their colony and set all together, at the same time, in the initial loggia of the apparatus, and those located in this loggia as well as in the free loggia were counted after 5 seconds, 2, 4, 6, 8 and 10 minutes. The numbers obtained for the two colonies were added (Table 4). The total numbers obtained for ants under stevia diet were statistically compared to those previously obtained for ants under sugar diet using the non parametric Wilcoxon test ${ }^{25}$.

\subsection{Ants' Preference between Stevia and Sugar}

Fifteen ants of colony A, as well as of colony B, were transferred into a small tray $(15 \mathrm{~cm} \times 7 \mathrm{~cm} \times 5 \mathrm{~cm})$, the inner borders of which being covered with talc to prevent escape, and in which two tubes $(\mathrm{h}=2.5 \mathrm{~cm}$, diam. $=0.5$ $\mathrm{cm}$ ) were laid, one containing sugar water, the other an aqueous solution of stevia (the same as that used during the experimental work), each tube being plugged with cotton. In one of the trays, the tube containing stevia was located on the right; in the other tray, it was located on the left (Figure $2 \mathrm{E}$ ). The ants drinking each kind of liquid food were counted 12 times in $15 \mathrm{~min}$, the mean values being then established for each kind. They were statistically compared to the values expected if ants randomly went drinking each kind of liquid, using the non parametric goodness of fit $\chi^{2}$ test ${ }^{25}$. 
Table 4. Effect of stevia diet on ants' brood caring behavior and cognition

\begin{tabular}{|c|c|c|c|c|}
\hline Diet $\rightarrow$ & \multicolumn{2}{|c|}{ Sugar water } & \multicolumn{2}{|c|}{ Stevia } \\
\hline \multicolumn{5}{|l|}{$\begin{array}{l}\text { Brood caring: } \\
\mathrm{n}^{\circ} \text { of not re entered larvae after }\end{array}$} \\
\hline $5 \mathrm{sec}$ & \multirow{2}{*}{\multicolumn{2}{|c|}{9}} & \multicolumn{2}{|c|}{9} \\
\hline $2 \mathrm{~min}$ & & & \multicolumn{2}{|c|}{7} \\
\hline $4 \mathrm{~min}$ & \multicolumn{2}{|c|}{6} & \multicolumn{2}{|c|}{6} \\
\hline $6 \mathrm{~min}$ & \multicolumn{2}{|c|}{4} & \multicolumn{2}{|c|}{5} \\
\hline $8 \mathrm{~min}$ & \multicolumn{2}{|c|}{2} & \multirow{2}{*}{\multicolumn{2}{|c|}{$\begin{array}{l}3 \\
0\end{array}$}} \\
\hline $10 \mathrm{~min}$ & \multicolumn{2}{|c|}{0} & & \\
\hline $\begin{array}{l}\text { Cognition: } \mathrm{n}^{\circ} \text { of ants in front and } \\
\text { beyond the twists and turns after }\end{array}$ & in front & beyond & in front & beyond \\
\hline $5 \mathrm{sec}$ & 25 & 0 & 26 & 0 \\
\hline $2 \mathrm{~min}$ & 18 & 1 & 20 & 0 \\
\hline $4 \mathrm{~min}$ & 15 & 1 & 16 & 0 \\
\hline $6 \mathrm{~min}$ & 14 & 2 & 13 & 2 \\
\hline $8 \mathrm{~min}$ & 13 & 4 & 11 & 4 \\
\hline $10 \mathrm{~min}$ & 9 & 5 & 7 & 5 \\
\hline
\end{tabular}

\subsection{Ants' Stevia Consumption Comparatively with that of Sugar}

While ants were under stevia diet, during two days, three times per day, the ants of the six colonies present on the aqueous solution of stevia were counted, and the mean value of each count established. After the experimental work, including the assessment of the ants' acceptance of stevia, the solutions of stevia were removed and the ants provided with aqueous solutions of sugar, which had the same sweetened intensity than the solutions of stevia, but not necessary the same taste. The ants of the six colonies present on these solutions were counted at the same time, under the same conditions as when they were counted on the stevia solutions. The six means obtained for ants under stevia diet were statistically compared to the six means obtained for ants under sugar diet using the non parametric test of Wilcoxon ${ }^{25}$.

\section{Results}

\subsection{Food Consumption}

Under stevia diet, ants consumed somewhat less meat food than when under sugar diet (Table 1, meanly $0.94 \mathrm{vs}$ 1.30 ants counted on the food; Figure 2 A). However, such a difference was not significant. It can thus be deducted that stevia does not impact, and surely does not increase, the individuals' food consumption.

\subsection{Linear and Angular Speed}

These traits were not at all impacted by stevia. The ants went on moving at the same speed of locomotion (13 $14 \mathrm{~mm} / \mathrm{s}$ ) and with the same sinuosity as when under sugar diet (about 140 angular degrees/cm) (Table 2). Meanwhile, it was observed, without quantifying it, that they foraged a little more under stevia diet.

\subsection{Precision of Reaction}

Under stevia diet, the ants went on correctly orienting themselves towards an isolated worker's head, a source of alarm pheromone. Meanly, their orientation equaled 33.7 angular degrees which is not statistically different from the ants' orientation under a sugar diet (30.8 angular degrees) (Table 2, line 3).

\subsection{Trail Following Behavior}

Ants under stevia diet did not walk along a blank circumference (Table 2, line 4, blank). On a circumference marked with the species trail pheromone, they duly followed the circular line along meanly 9 arcs of 10 degrees (Figure 2 B, Table 2, line 4, test). Even if being slightly lower, this score did not statistically differ from that of ants under sugar diet (meanly 10 arcs of 10 degrees; $\chi^{2}=$ $2.51, \mathrm{df}=3$, NS). Thus, a stevia diet did not statistically impact the individuals' response to their pheromones (i. e. trail and alarm pheromones). 


\subsection{Audacity}

Comparatively with what we saw while working on ants under sugar diet, we observed a little more ants coming onto the apparatus when we experimented on ants under stevia diet. The numerical results reflected this observation: meanly 1.38 ants under stevia diet were counted on the apparatus while 0.85 ants under sugar diet had been there counted. Such a difference in ants' audacity (or tendency in exploring) was significant: $\mathrm{P}=$ $0.0095 \sim 0.01$.

\subsection{Visual and Olfactory Conditioning and Memory}

To summarize, stevia did not statistically affect these traits (Figure $2 \mathrm{C}$; Table 3).

Under stevia diet, ants acquired visual conditioning slightly more slowly than when under sugar diet but reached a similar score. The difference of ants' conditioning ability between the two kinds of diet was not significant. Under stevia diet, the ants lost their conditioning a little more slowly than ants under sugar diet, but retained a similar conditioning value. The difference of ants' visual memory between the two kinds of diet was at the limit of significance.

Under stevia diet, the ants acquired olfactory conditioning somewhat more slowly than under sugar diet, reaching however a similar score. The small difference between the two kinds of diet was not significant. Under stevia diet, the ants lost their olfactory conditioning somewhat more slowly than under sugar diet but retained the same amount of conditioning. This difference between the two diets was not significant.

\subsection{Brood Caring Behavior}

While experimenting, we observed that ants under stevia diet duly took care of their larvae (Figure $2 \mathrm{D}$ ). The obtained numerical results effectively revealed that ants re-entered the larvae artificially removed from their nest exactly (at the same speed, with the same care) as did ants under sugar diet (Table 4)

\subsection{Cognition}

Even if ants under stevia diet took slightly more time than ants under sugar diet to leave the small initial loggia and to reach the large free loggia beyond the twists and turns, in fine, the difference of ants' behavior (that requiring cognitive ability) between the two kinds of diet was not significant. Cognition was thus not impacted by a stevia instead of sugar diet.

\subsection{Preference between Stevia and Sugar}

Confronted to a solution of stevia and to one of sugar, the two solutions having the same sweetened value, the ants firstly came equally onto the two solutions. Then, in the course of 12 minutes, they progressively were more and more numerous to come on the sugar solution (observation of the first author and of a naïve observer, blind to the situation). Finally, the ants drank essentially the sugar solution (Figure $2 \mathrm{E}$ ). The total number of ants counted on the sugar solution was 18 for colony A and 29 for colony B, while it was 14 for colony A and 7 for colony B on the stevia solution. The sums of the counts, i.e. 47 (sugar) vs 21 (stevia), statistically differed from the numbers expected if ants randomly went onto the two sweetened solutions $\left(\chi^{2}=9.94, \mathrm{df}=1, \mathrm{P}<0.01\right)$. Thus, ants preferred sugar (saccharose) though they accepted to consume stevia in the absence of it. This result explains why ants had a tendency in foraging everywhere and coming onto an unknown apparatus. This incited us to look to the ants' consumption of a stevia and a sugar solution.

\subsection{Stevia Consumption Comparatively with that of Sugar}

When we gave solutions of stevia to the ants of the $6 \mathrm{col}$ onies after having provided them with only pure water, few ants came drinking the sweeten water. The assessment of this food consumption revealed that meanly 0.36 ants were present on the stevia solution. After the entire experimental work, when we removed the stevia solutions and provided solutions of saccharose to the ants, these insects were immediately numerous to drink the sugar solutions. The assessment of this food consumption, made exactly as that of the stevia solution, showed that meanly 8.00 ants were present on the sugar solutions. The difference between the ants' consumption of the two kinds of sweeten water was significant: $\mathrm{N}=6, \mathrm{~T}=21, \mathrm{P}=0.016$. This result is in agreement with - and explains - other results, i.e. the ants' choice between sugar and stevia solution as well as their tendency to forage and to move on an unknown apparatus while under stevia diet, the ants looking then after sugar (saccharose). 


\section{Discussion}

Sweeteners are nowadays more and more consumed all over the word. The most used are aspartame and stevia. We have already studied aspartame, using ants as biological models, confirming other studies on this sweetener and defining some of its effects ${ }^{3}$. Here we made an identical work on stevia. Here under, we summarize our results and compare them to those obtained with aspartame, briefly relate what is actually known about stevia (potential safety, stability and approved use) and emit a suggestion about a safe use of sweeteners.

We found that stevia:

- does not impact food consumption,

- does not affect locomotion,

- does not change the ants' ability to orient themselves towards a source of alarm pheromone,

- does not alter the ants' trail following behavior

- increases a little audacity i.e. the tendency to climb on a tower,

- does not impact visual and olfactory conditioning, as well as visual and olfactory memory,

- does not affect brood caring behavior,

- does not impact cognition.

On the contrary, we found ${ }^{3}$ that aspartame:

- increases food consumption,

- increases speed of locomotion,

- reduces the ants' ability in correctly orienting themselves,

- impacts the ants' trail following behavior,

- largely increases audacity,

- largely impacts visual and olfactory conditioning and memory,

- affects brood caring behavior,

- reduces cognition.

Obviously, the natural sweetener stevia, a true glycoside, is without apparent adverse effects, while the artificial sweetener aspartame, which is not a glycoside, has many immediate ethological and physiological adverse effects.

We also found that ants prefer saccharose to stevia. Having the choice between stevia and saccharose, they progressively chose the latter. For ants, stevia is thus perhaps not as sweet as saccharose. Under stevia diet, the ants were not very numerous in consuming that sweetener. On the contrary, confronted to a solution of aspartame and to one of sugar, the ants soon and nearly exclusively chose the sugar, but in absence of saccharose, they were very numerous in consuming aspartame. They might so consume large amounts of that sweetener which moreover incites to eat ${ }^{3}$. These last observations lead us once more to recommend the use of stevia and not of aspartame.

What is actually known about the effects of stevia? In his thorough review on the subject ${ }^{30}$, Kumar concludes that, under normal doses, stevia has no mutagenicity, is not carcinogenic, and does not impact the renal function. At high doses, it only somewhat increases the renal plasma flow. Given intravenously, it reduces blood pressure without changing anything else. Moreover, stevia was shown to have some antimicrobial properties. It was thus concluded that stevia is a safe sweetener.

All sweetened food, carbohydrate or not, may enhance the cephalic phase of recognition of the sweet taste, the expectation of sweet food, and the use of glucose available in the organism ${ }^{31}$. If the organism effectively receives glycosides, it will not want to eat more, or to search for glycosides. If it receives a small but sufficient amount of glycoside, it will not or only slightly want to search after. If it receives no glycoside and imperatively needs such kind of substance, it will search for it. This is reported by Anderson ${ }^{1}$ in a review about sugar and health. Concerning aspartame and stevia, stevia is a true glycoside and so will not incite to eat more but, as it has not a very pleasant taste, it may incite to look for a nicer sweeten food. Aspartame is not a glycoside, and its consumption often in large amount due to its very nice sweetened taste, may lead to search for food, glycosides essentially, and to eat. This has been shown in ${ }^{32}$ with a probability of $\mathrm{P}<0.01$ (even if the authors wrote the contrary). For this important trait also, stevia is preferable to aspartame.

Xili et $\mathrm{al}^{33}$ gave steviosides to rats and looked to the animals' growth, food consumption, hematological, urinal and clinical parameters and mortality after 6, 12 and 24 months, without finding differences with control groups. The authors concluded that a daily intake of 7.938 $\mathrm{mg} / \mathrm{kg}$ stevioside by humans is acceptable. A metabolite of steviosides is steviol. Working on pregnant hamsters intubated with steviol, Wasuntarawat et $\mathrm{al}^{34}$ found that doses of $0.75 \mathrm{~g}$ and $1.0 \mathrm{~g} / \mathrm{kg} /$ day were toxic for dams and fetuses, while a dose of $0.25 \mathrm{gr} / \mathrm{kg} /$ day of steviol was not. Such a dose correspond to $625 \mathrm{mg} / \mathrm{kg} /$ day of stevioside, what is about 80 times more than the dose usually recommended for humans $(7.9 \mathrm{mg} \mathrm{x} 80=632 \mathrm{mg}$ ). 
Carakostas and co-authors ${ }^{35}$ have written a survey about steviol glycosides. The steviosides are stable for three years when kept as a dry powder, and somewhat less stable in aqueous solution. Rebaudioside A is the most stable compound, the most at a $\mathrm{pH}$ of $4-8$. It stays also stable under light and high temperature. Concerning the safety of stevioside (in fact that of their metabolitical compound steviol), neither carcinogenicity nor clinical toxicity could be noted, the numerous studies on genetic toxicity were negative, but some taste aversion and less food consumption were observed (a fact we also observed on ants) causing body weight loss. As for adverse effects of stevioside on fertility (an information circulating on internet), highly scientific and meticulous studies have shown that such effects do not exist. Consequences of a stevia diet for persons suffering from hypotension or from type 2 diabetes were studied many times and, finally, no treatment-related effects were observed. Neither steviosides nor rebaudioside A were found to be cariogenic in several studies on the subject.

On the basis of the very numerous studies made on steviosides, an ADI (Amount of food Additive that can be Ingested daily over a life time without health risk) for these substances was tentatively established ${ }^{35}$. Such an evaluation as well as the regulatory status of leaves or extracts of $S$. rebaudiana largely differ between countries, ranging from "steviosides are safe" to "steviosides are prohibited", which causes confusion.

Finally, as inferred from the present experimental study on ants, glycosides extracted from $S$. rebaudiana are not toxic, at least at the approved daily dose (the quantity of stevia daily consumed by ants was similar to that dose). Their only inconvenient may be that they have not a sweetened taste as pleasant as that of saccharose. Aspartame has such a nice taste and even nicer. Humans unaware about the effects of these two sweeteners will automatically chose aspartame, not stevia. We recently experimentally showed that an adequate mixture of these two sweeteners associate the safety of stevia and the sweetened character of aspartame. Ants under such a mixed diet did not eat more or less, and presented no physiological or ethological perturbations ${ }^{36}$.

\section{Conclusion}

The natural glycoside stevia used as a sweetener in South America and Asia, allowed in 1995 in USA, and in 2011 in
Europe as a food additive (E 960), but still not approved by Health Canada, appears to be a safe product, having apparently no adverse physiological and ethological effect. In comparison, aspartame, the sweetener the most consumed in North America and Europe, largely affects the individuals' physiology and ethology, and hydrolyzes into dangerous compounds. Stevia is thus far more recommended than aspartame as a sweetener. However, contrary to aspartame, it is not of the nicest sweetened taste. We recently experimentally found that a large amount of stevia mixed to a small one of aspartame constitute a safe and nicely sweetener ${ }^{36}$.

\section{Acknowledgements}

We are very grateful to Dr Annapurna whose editorial suggestions allowed us to largely improve our paper

\section{Conflict of Interest}

The authors declare having no conflict of interest.

\section{References}

1. Anderson GH. Sugar and health: a review. Nutrition Research. 1997; 17:1485-98.

2. Tandel KR. Sugar substitutes: health controversy over perceived benefits. J Pharmacology and Pharmacotherapeutics. 2011; 2:236-43.

3. Cammaerts M-C, Cammaerts R. Aspartame increases food demand and impacts behavior: a study using ants as models. Acta Biomedica Scientia. 2016; 3:9-23.

4. Just T, Pau HW, Engel U, Hummel T. Cephalic phase insulin release in healthy humans after taste stimulation. Appetite. 2008; 51:622-7.

5. Lipinsky VRG-W. Sweeteners. In Biotechnology of Food and Feed Additives. Lorn $\mathrm{H}$ and Czermak $\mathrm{P}$ eds. Adv Biochem Eng Biothechnol. Berlin, Heidelberg: Springer; 2014; 143:1-28.

6. Available from https://en.wikipedia.org/wiki/Steviol_glycoside

7. Available from www.axonepharma.be

8. Geums JM. Stevioside. Phytochemistry. 2007; 64:913-21.

9. Kolb B, Whishaw IQ. Neuroscience \& cognition: cerveau et comportement. New York: Eds Worth Publishers, Basing Stoke; 2002. p. 635.

10. Wolf FW, Heberlein U. Invertebrate models of drug abuse. J Neurobiol. 2003; 54:61-178. Available from http://dx.doi. org/10.1002/neu.10166. 
11. Andre RG, Wirtz RA, Das YT. Insect Models for Biomedical Research. In A. D. Woodhead (Ed.), Nonmammalian Animal Models for Biomedical Research. (November 13, 2008). Boca Raton, FL: CRC Press; 1989.

12. Passera L, Aron S. Les fourmis: comportement, organisation sociale et évolution. Ottawa, Canada: Les Presses Scientifiques du CNRC; 2005. p. 480.

13. Cammaerts M-C. Navigation system of the ant Myrmica rubra (Hymenoptera, Formicidae). Myrmecol News. 2012; 16:111-21.

14. Passera L. La véritable histoire des fourmis. Librairie Fayard. 2006. p. 340.

15. Cammaerts M-C. Etude démograpique annuelle des sociétés de Myrmica rubra L. des environs de Bruxelles Ins Sociaux. 1977; 24:147-61.

16. Rachidi Z, Cammaerts M-C, Debeir O. Morphometric study of the eye of three species of Myrmica (Formicidae). Belg J Entomol. 2008; 10:81-91.

17. Cammaerts M-C. Visual vertical subtended angle of Myrmica ruginodis and Myrmica rubra (Formicidae, Hymenoptera). Bull Soc R Belg Ent. 2011; 147:113-20.

18. Cammaerts M-C. Myrmica rubra workers' visual perception (Hymenoptera, Formicidae). Belg J Zool. 2013; 143:69-78.

19. Cammaerts M-C. Olfactory and visual operant conditioning in the ant Myrmica rubra (Hymenoptera, Formicidae). Bull Soc R Ent Belg. 2012; 148:199-208.

20. Cammaerts M-C. Recruitment to food in Myrmica rubra. Biology of Behaviour. 1978; 4:159-72.

21. Cammaerts M-C, Cammaerts R. Ontogenesis of ants' cognitive abilities (Hymenoptera, Formicidae). Advanced Studies in Biology. 2015; 7:335-50.

22. Cammaerts M-C, Gosset G. Impact of age, activity and diet on the conditioning performance in the ant Myrmica ruginodis used as a biological model. Int J Biology. 2014; 6:10-20. ISSN 1916-9671 E-ISSN 1916-968X

23. Cammaerts M-C, Gosset G, Rachidi Z. Some physiological and ethological effects of nicotine; studies on the ant Myrmica sabuleti as a biological model. Int J Biology. 2014; 6:64-81.

24. Cammaerts M-C, Cammaerts R. Effects of buprenorphine and methadone, two analgesics used for saving humans dependent on morphine consumption. Int J Pharmaceutical Science Invention. 2015; 4:1-19.
25. Siegel S, Castellan NJ. Nonparametric statistics for the behavioural sciences. Singapore: McGraw-Hill Book Company; 1989.

26. Cammaerts-Tricot M-C. Phéromone agrégeant les ouvrières de Myrmica rubra. J Ins Physiol. 1973; 19:1299-315.

27. Cammaerts M-C, Morel F, Martino F, Warzée N. An easy and cheap software-based method to assess two-dimensional trajectories parameters. Belg J Zoology. 2012; 142:145-51.

28. Cammaerts M-C, Rachidi Z, Cammaerts D. Collective operant conditioning and circadian rhythms in the ant Myrmica sabuleti (Hymenoptera, Formicidae). Bull Soc R Belg Entomol. 2011; 147:142-54.

29. Cammaerts M-C. Colour vision in the ant Myrmica sabuleti Meinert, 1861 (Hymenoptera: Formicidae). Myrmecol News. 2007; 10:41-50.

30. Kumar SK. Stevia (Stevia rebaudiana), a bio-sweetener: a review. Int J Food Sciences and Nutrition. 2009; 61:1-10. DOI: 10.3109/09637480903193049

31. Ferland A, Brassard P, Poirier P. Is aspartame really safer in reducing the risk of hypoglycemia during exercise in patients with type 2 diabetes? Diabetes Care. 2007; 30:59.

32. Anton SD, Martin CK, Han H, Coulon S, Cefalu WT, Geiselman P et al. Effects of stevia, aspartame, and sucrose on food intake, satiety, and postprandial glucose and insulin levels. Appetite. 2010; 55:37-43.

33. Xili L, Chengjiany B, Eryi X, Reriming S, Yuengming W, Haodone S, Zhiyian H. Chronic oral toxicity and carcinogenicity study of stevioside in rats. Food and Chemical Toxicology. 1992; 30:957-65.

34. Wasuntarawat C, Temcharoen P, Toskulkao C, Mungkornkarn P, Suttajit M, Glinsukon T. Developmental toxicity of steviol, a metabolite of stevioside, in the hamster. Drug and Chemical Toxicology. 1998; 21:207-22.

35. Carakostas M, Prakash I, Kinghorn AD, Wu CD, Soejarto DD. Steviol Glycosides. Chapter 11 in 'Alternative Sweeteners'. 4th ed. Lyn O’Brien Nabors, CRC Press, Taylor \& Francis, FL; 2011. p. 159-80.

36. Cammaerts M-C, Cammaerts R, Dero A. A 0.123\% Stevia/ Aspartame 91/9 Aqueous Solution Balances the Effects of the Two Substances, and may thus be a Safer and Tastier Sweetener to be Used. J Pharmacy and Nutrition Sciences. 2015; 5(4): 236-248. DOI: 10.6000/1927-5951.2015.05.04.4 (published 08 January 2016). 